\title{
Identifikasi Dermatofita Pada Sisir Tukang Pangkas Di Kelurahan Jati Kota Padang
}

\author{
Hifzil Husni ${ }^{1}$, Ennesta Asri ${ }^{2}$, Rina Gustia ${ }^{2}$
}

\begin{abstract}
Abstrak
Tinea kapitis merupakan kelainan kulit pada daerah kepala berambut yang disebabkan oleh jamur dermatofita. Jamur dermatofita dapat ditularkan secara langsung dari manusia, hewan, tanah dan secara tidak langsung melalui benda seperti handuk, topi dan sisir yang digunakan bergantian. Alat pangkas dapat menjadi sumber penularan infeksi secara tidak langsung. Tujuan penelitian ini adalah mengidentifikasi dermatofita pada sisir tukang pangkas di kelurahan Jati Padang. Jenis penelitian ini adalah deskriptif observasional. Populasi dalam penelitian ini adalah seluruh sisir yang digunakan tukang pangkas di Kelurahan Jati Kecamatan Padang Timur Kota Padang. Teknik pengambilan sampel pada penelitian ini adalah total sampling sebanyak 20 sampel. Penelitian ini dilaksanakan dari Agustus 2017 sampai Maret 2018. Hasil penelitian ditemukan dua spesies dermatofita yaitu Trichophyton Mentagrophytes (10\%) dan Trichophyton Schoenleinii (5\%). Simpulan penelitian ini adalah sebagian kecil sisir tukang pangkas di Kelurahan Jati terdapat dermatofita, oleh karena itu sisir tukang pangkas dapat menjadi media transmisi sumber infeksi yang baik pada masyarakat.
\end{abstract}

Kata kunci: dermatofita, sisir, tukang pangkas

\section{Abstract}

Tinea capitis is an infection caused by dermatophyte fungi of scalp hair follicles and the surrounding skin. Dermatophytes are spread by direct contact from other people, animals, soil, as well as indirectly from fomites that infected exfoliated skin or hair in towels, caps and combs. The barber's tools could serve as a potential source and transmision of fungal infection indirectly. The objective of this study was to identify the species of dermatophyte on barber's comb in Jati Padang. This study used descriptive observational method. Population in this research were all of comb that used by barbers in Jati. The sampling technique was total sampling and the entire population was the research subject. This research was held from August 2017 until March 2018. This study found Trichophyton Mentagrophytes (10\%) and Trichophyton Schoenleinii (5\%) on examination of fungal culture. The conclusion of this study showed that 15\% barber's comb in Jati have found dermatophytes. Barber's comb are important sources and may play an important role in spreading dermatophyte infections among people.

Keywords: dermatophyte, comb, barber

\footnotetext{
Affiliasi penulis: 1. Prodi Kedokteran Fakultas Kedokteran Universitas Andalas Padang (FK Unand), 2. Bagian Kulit dan Kelamin FK Unand/RSUP Dr. M. Djamil Padang.

Korespondensi: Hifzil Husni, Email: hifil.husni@gmail.com Telp: 085271169499
}

\section{PENDAHULUAN}

Dermatofita merupakan golongan jamur yang melekat dan tumbuh pada jaringan keratin, jamur menggunakan jaringan keratin sebagai sumber makanannya. Jaringan yang mengandung keratin ialah jaringan seperti stratum korneum kulit, kuku, dan rambut pada manusia. Kemungkinan besar terjadinya infeksi pada daerah tersebut pada manusia. Selain menyerang jaringan keratin pada manusia dermatofita juga menyerang kulit hewan, sehingga penularan jamur dermatofita dapat terjadi jika berkontak dengan hewan yang terinfeksi. ${ }^{1}$ Saat sekarang ini sudah ditemukan 41 spesies dermatofita, terdiri dari 17 
spesies Microsporum, 22 spesies Trichophyton, 2 spesies Epidermophyton. $^{2}$

Pertumbuhan jamur sangat mudah sesuai dengan kecocokan dengan sel inang dan lingkungannya. Pada umumnya jamur tumbuh dan berkembang baik pada lingkungan dengan suhu 25$28^{0} \mathrm{C}$ begitu juga dengan dermatofita. Selain faktor lingkungan, infeksi pada kulit manusia dipengaruhi oleh beberapa faktor seperti; higiene individu yang rendah, tempat tinggal atau pemukiman yang padat, pakaian yang tidak menyerap keringat, atau bagian tubuh yang sering tertutup lama oleh pakaian, sepatu, maupun topi. Biasanya infeksi jamur sering terjadi pada populasi dengan tingkat sosioekonomi yang rendah, hal ini terjadi karena kurangnya pengetahuan dan sikap individual terhadap resiko timbulnya infeksi dan transmisi dari jamur. ${ }^{3}$

Penyakit kulit yang disebabkan oleh golongan jamur dermatofita ini disebut dengan dermatofitosis. Dermatofitosis disebut juga dengan tinea dan memiliki variasi sesuai dengan lokasi anatominya seperti tinea kapitis, tinea barbae, tinea kruris, tinea pedis dan tinea korporis. ${ }^{1}$

Penyakit ini sering terjadi pada anak-anak dengan usia dominan 3 sampai 7 tahun, dapat juga mengenai neonatus dan dewasa. ${ }^{4}$

Pada profil dermatofitosis di RSUP Prof. dr. RD. Kandou Manado tahun 2012, didapatkan tinea kruris $55,38 \%$, tinea korporis $26,16 \%$, selanjutnya tinea kapitis $9,23 \%{ }^{5}$

Berdasarkan profil kesehatan Kota Padang tahun 2014, penyakit infeksi kulit merupakan sepuluh penyakit terbanyak di Kota Padang tahun 2014 . $^{6}$ Dalam data publikasi Kota Padang, penyakit infeksi kulit berada pada urutan ke dua penyakit terbanyak di Kecamatan Padang Timur. ${ }^{7}$

Penularan dermatofitosis dapat secara langsung dari manusia ke manusia (anthropophilic organisms), dari tanah ke manusia (geophilic organisms), dan dari hewan ke manusia (zoophilic organisms). Transmisi dermatofita juga dapat terjadi secara tidak langsung melalui benda lain yang dapat berperan menjadi media penularan agen infeksi seperti handuk, topi, dan sisir yang digunakan bergantian.
Benda atau alat yang digunakan bergantian sering ditemukan di tempat umum seperti tempat pangkas, toilet dan sarana umum lainnya.,

Tinea kapitis atau yang sering dikenal sebagai kurap kulit kepala merupakan kelainan kulit pada daerah kepala berambut yang disebabkan oleh jamur dermatofita. Tinea kapitis dapat disebabkan oleh genus Trichophyton dan Microsporum. ${ }^{9}$

Tukang pangkas (barber) adalah salah satu profesi penting di kalangan masyarakat. Tukang pangkas memanfaatkan instrumen seperti pisau, gunting dan sisir yang membuatnya perlu evaluasi bahaya kesehatan dan mengidentifikasi terkait transmisi infeksi. Penyakit yang paling penting terkait dengan praktik tukang pangkas adalah tinea kapitis, infestasi kutu kepala, infeksi stafilokokus, scabies, hepatitis dan HIV. $^{10}$ Alat pangkas dapat menjadi sumber penularan infeksi secara langsung maupun tidak langsung dan beberapa infeksi dapat terjadi dengan atau tanpa merusak kulit, oleh karena itu peralatan harus dibersihkan sebelum dan sesudah digunakan. $^{11}$

Kota Padang dengan rata-rata suhu udara $\left(26,8^{\circ} \mathrm{C}\right)$ dan kelembaban (83\%) yang tinggi dapat menjadi tempat pertumbuhan dan perkembangan jamur yang baik. $^{7}$

Penelitian yang dilakukan oleh Enemuor et al tahun 2012 menyimpulkan bahwa alat pangkas dapat menyebarkan penyakit infeksi kulit seperti scabies, dermatitis dan dermatofitosis. ${ }^{12}$ Pada peralatan tukang pangkas di Mubi Adamawa State-Nigeria dalam penelitian David et al tahun 2010 juga ditemukan adanya Microsporum audouinii dan Candida albicans. $^{13}$ Di Medan, penelitian Benny tahun 2015 ditemukan Penicillium sp pada sisir tukang pangkas yang memiliki proporsi terbesar yaitu 26,7\%, sedangkan jamur dari golongan dermatofita memiliki proporsi $20 \%{ }^{14}$

\section{METODE}

Jenis penelitian ini adalah deskriptif dengan rancangan cross sectional yaitu subyek penelitian diobservasi sebanyak satu kali dan variabel diukur langsung pada pemeriksaan tersebut. Penelitian telah 
dilakukan dari bulan Agustus 2017 - Maret 2018 di Kelurahan Jati, Padang, Sumatera Barat.

Populasi penelitian ini adalah sisir yang digunakan tukang pangkas pria di Kelurahan Jati, Kecamatan Padang Timur, Padang. Sampel penelitian yang dipilih adalah populasi yang memenuhi kriteria inklusi. Kriteria inklusi subjek: Sisir yang telah digunakan dan masih digunakan, tukang pangkas bersedia menjadi subjek penelitian dengan menandatangani lembar persetujuan ikut serta yang telah disediakan. Spesimen diambil menggunakan lidi dan dimasukkan kedalam amplop.

Data diperoleh dengan pemeriksaan $\mathrm{KOH}$ dan kultur untuk identifikasi dermatofita yang tumbuh. Pemeriksaan dilakukan di Laboratorium Mikrobiologi FK Unand.

\section{HASIL}

Tabel 1. Distribusi sampel berdasarkan riwayat sisir dibersihkan dengan air dan sabun

\begin{tabular}{lcc}
\hline Riwayat sisir dibersihkan & $\mathbf{f}$ & $\%$ \\
\hline Pernah & 6 & 30 \\
Tidak pernah & 14 & 70 \\
\hline Jumlah & 20 & 100 \\
\hline
\end{tabular}

Berdasarkan Tabel 1 terlihat sebagian sisir yang digunakan tukang pangkas di kelurahan jati tidak pernah dibersihkan yaitu sebanyak 14 sisir, sedangkan jumlah sisir yang pernah dibersihkan dengan air dan sabun sebanyak 6 sisir.

Tabel 2. Distribusi hasil pemeriksaan $\mathrm{KOH}$

\begin{tabular}{lcc}
\hline Hasil KOH & $\mathbf{f}$ & $\%$ \\
\hline Positif (+) & 0 & 0 \\
Negatif $(-)$ & 20 & 100 \\
\hline Jumlah & 20 & 100 \\
\hline
\end{tabular}

Tabel 2 menunjukkan bahwa 20 sampel (100,\%) mendapatkan pemeriksaan $\mathrm{KOH}$ negatif.
Tabel 3. Distribusi hasil kultur

\begin{tabular}{lcc}
\hline Golongan & $\mathbf{f}$ & $\%$ \\
\hline Tidak tumbuh koloni & 0 & 0 \\
Tidak teridentifikasi & 1 & 5 \\
Dermatofita & 3 & 15 \\
Jamur lain & 16 & 80 \\
\hline Jumlah & 20 & 100 \\
\hline
\end{tabular}

Berdasarkan Tabel 3 dapat dilihat bahwa dari 20 sampel sisir yang diteliti, terdapat 3 sampel (15\%) terdapat dermatofita, sebanyak 16 sampel (80\%) terdapat jenis jamur lain, dan satu sampel (5\%) tidak dapat diidentifikasi. Pada pemeriksaan kultur, semua sampel tumbuh dan berkoloni di Sabouraud Dextrose Agar (SDA).

Tabel 4. Distribusi sampel berdasarkan spesies jamur

\begin{tabular}{lcc}
\hline Spesies jamur & $\mathbf{f}$ & $\%$ \\
\hline Tidak tumbuh koloni & 0 & 0 \\
Tidak teridentifikasi & 1 & 5 \\
Aspergillus fumigatus & 5 & 25 \\
Aspergillus niger & 5 & 25 \\
Candida Sp & 2 & 10 \\
Penicillium Sp & 3 & 15 \\
Rhizopus Sp. & 1 & 5 \\
Trichophyton mentagrophytes & 2 & 10 \\
Trichophyton schoenleinii & 1 & 5 \\
\hline Jumlah & 20 & 100
\end{tabular}

Berdasarkan Tabel 4 dapat dilihat bahwa jamur terbanyak dari hasil kultur sisir adalah Aspergillus niger dan Aspergillus fumigatus yang merupakan golongan Jamur lain dengan kontaminasi sisir masingmasing sebanyak 25\%. Golongan jamur lain yaitu Penicillium sp (15\%), Rhizopus sp (5\%) dan Candida $s p(10 \%)$, sedangkan dermatofita didapatkan pada 3 sampel, yaitu dua Trichophyton mentagrophytes (10\%) dan satu Trichophyton schoenleinii (5\%). 


\section{PEMBAHASAN}

Berdasarkan pemeriksaan terhadap 20 sampel sisir tukang pangkas yang diambil dari tempat pangkas di kelurahan Jati, ditemukan 3 sampel terdapat jamur dermatofita, sedangkan 16 sampel lainnya terdapat jamur bukan dermatofita. Sehingga dapat disimpulkan bahwa 85 \% sampel sisir yang diteliti dalam penelitian ini bebas dari dermatofita. Temuan jamur dermatofita pada 3 dari 20 sampel yang diteliti menunjukkan bahwa sisir dapat berperan sebagai transmisi sumber infeksi dermatofita.

Hasil pemeriksaan $\mathrm{KOH} 20 \%$ didapatkan bahwa semua sampel (100\%) tidak ditemukan hifa maupun spora. Hasil ini berbeda dengan penelitian di Medan tahun 2016 yang mendapatkan hasil $\mathrm{KOH}$ positif pada semua sampel sisir (100\%), sedangkan penelitian yang dilakukan pada 3 kota di Nigeria dengan peneliti yang berbeda tidak menggunakan pemeriksaan $\mathrm{KOH}$ dalam penelitiannya. Pemeriksaan mikroskopik sediaan langsung $\mathrm{KOH}$ memiliki sensitivitas dan spesifisitas yang rendah sehingga sering didapatkan hasil negatif palsu Penelitian di Palembang tahun 2013 mendapatkan sensitivitas pemeriksaan $\mathrm{KOH}$ pada onikomikosis sebesar 54\% dan spesifisitas $\mathrm{KOH}$ sebesar $44 \%$. Hal ini berarti kemampuan pemeriksaaan $\mathrm{KOH}$ untuk memberikan hasil positif sebesar 54\%. Hasil ini berbeda dengan penelitian yang telah dilakukan dimana hasil pemeriksaan $\mathrm{KOH}$ pada semua sampel negatif. Faktor yang mempengaruhi hasil pemeriksaan $\mathrm{KOH}$ diantaranya yaitu pengalaman yang dimiliki oleh pemeriksa, cara pengambilan sampel yang tidak tepat yaitu pemilihan area, pengambilan jumlah spesimen, dan membersihkan area yang akan diambil dengan alkohol. $^{3,12,13,15}$

Jamur dermatofita terdiri dari tiga genus yaitu Epidermophyton (E), Microsporum (M), dan Trichophyton (T). Dermatofita yang biasanya menyebabkan tinea kapitis yaitu Microsporum audouinii, M. Canis, T. mentagrophytes, T. tonsurans, T. rubrum, dan T. Schoenleinii. ${ }^{4}$ Dalam penelitian ini, jamur golongan dermatofita yang dijumpai adalah golongan Trichophyton. Jenis Trichophyton yang ditemukan pada penelitian ini yaitu T.mentagrophytes sebanyak dua sampel (10\%) dan T. Schoenleinii sebanyak satu sampel (5\%). Hal ini sejalan dengan penelitian di Medan dimana didapatkan T.mentagrophytes (6,7\%), T.Rubrum (6,7\%), T. Schoenleinii (3,3\%), dan T. Violaceum (3,3\%) pada sisir tukang pangkas. ${ }^{14}$ Penelitian yang dilakukan di Mubi, Nigeria pada tahun 2010 mendapatkan M. Audouinii dan Candida albicans pada alat tukang pangkas (Gunting, sisir, dan clippers). ${ }^{13}$ Pada penelitian ini tidak ditemukan dermatofita dari genus Microsporum, ini menunjukkan bahwa jenis jamur pada benda dipengaruhi oleh banyak faktor seperti epidemiologi pada setiap daerah, kontak dengan sumber infeksi, suhu lingkungan, kebersihan dan sebagainya. $^{16}$

Sampel yang diteliti juga dilihat dari riwayat sisir dibersihkan. Pada penelitian didapatkan 70\% sisir yang digunakan tidak pernah dibersihkan, 30\% sisir dibersihkan dengan cara dicuci dengan air dan sabun. Berdasarkan hasil pengamatan riwayat sisir dibersihkan, didapatkan 3 sampel sisir yang ditemukan dermatofita merupakan sampel yang tidak pernah dicuci. Pada 17 sampel yang tidak ditemukan dermatofita, 6 diantaranya pernah dicuci dan 11 sampel lainnya tidak pernah dicuci. Hal ini menjelaskan bahwa kurangnya kebersihan dapat menjadi salah satu faktor yang baik untuk pertumbuhan jamur, selain itu pemakaian sisir yang tidak dibersihkan pada tempat pangkas dapat meningkatkan resiko penularan infeksi kulit oleh jamur dari satu pelanggan ke pelanggan lainnya.

\section{SIMPULAN}

Dermatofita yang ditemukan pada sisir tukang pangkas di kelurahan Jati berasal dari genus Trichophyton yaitu Trichophyton mentagrophytes dan Trichophyton schoenleinii.

\section{DAFTAR PUSTAKA}

1. Kurniati, Cita Rosita SP. Etiopatogenesis dermatofitosis. Berkala IImu Kesehatan Kulit dan Kelamin. 2008;20(3):243-249.

2. Budimulja U, Bramono K, Widaty S. Mikosis, Dalam: Djuanda A, Hamzah M, Aisah S, editor (penyunting). Ilmu penyakit kulit dan kelamin. Edisi ke-6. Jakarta: Badan Penerbit FK UI;2011:103-16. 
3. Agustine $\mathrm{R}$, Perbandingan sensitivitas dan spesifisitas pemeriksaan sediaan langsung $\mathrm{KOH}$ $20 \%$ dengan sentrifugasi dan tanpa sentrifugasi pada tinea kruris (tesis). Padang: Andalas University; 2012.

4. Verma S, Hefferman MP. Superficial Fungal Infection: Dermatophytosis, Onichomycosis, Tinea Nigra, Piedra. Dalam: Wolff K, Goldsmith L, Katz S, Gilchrest B, Paller A, Leffell O, editor (penyunting). Fitzpatrick's Dermatology in General Medicine. Edisi ke-7. New York: McGraw-Hill; 2008. hlm.1807-21.

5. Bertus NVP, Pandaleke HEJ, Kapantow GM. Profil dermatofitosis di poliklinik kulit dan kelamin RSUP Prof. Dr. R. D. Kandou Manado periode Januari Desember 2012. Jurnal e-Clinic. 2015;3(2):733.

6. Dinas Kesehatan Kota Padang. Profil kesehatan kota Padang tahun 2014. Padang: Dinas Kesehatan Kota Padang; 2014.

7. Badan Pusat Statistik Kota Padang. Kecamatan Padang timur dalam angka. Padang: Badan Pusat Statistik Kota Padang; 2016.

8. Hainer BL, Dermatophyte infections. Charleston: American Family Physician. 2003;67(1):101-7.

9. James WD, Berger TG, Elston DM. Clinical Dermatology. Edisi ke-9. Kanada: WB Sounders Company; 2000.
10. Chanda SK, Khan KH. Sharing of razor blade in salons and risks of spreading HIV in Bangledesh. Poster exhibition. The 3rd IAS conference on HIV pathogenesis and treatment; 2004.10(5): 02.

11. Salami KK, Titiloye MA, Brieger WR, Otusanya SA. Observations of barbers' activities in Oyo State, Nigeria: implications for HIV/AIDS transmission. Int. Quart Comm. Health Edu. 2006; 24:319- 30.

12. Enemuor SC, Atabo AR, Oguntibeju OO, Evaluation of microbiological hazards in barbershops in a university setting. Nigeria: Academic Journals. 2012;7(9):1100-2.

13. David DL, Edward A, Zaruwa MZ, Addas PA. Barbing saloon associated fungal disease infection in Mubi, Adamawa State-Nigeria. World Journal of Medical Sciences. 2010;5(1):17-21.

14. Benny, Identifikasi dermatofita pada sisir tukang pangkas di Kelurahan Padang Bulan (skripsi). Medan: Fakultas Kedokteran Universitas Sumatera Utara; 2016.

15. Devianty L. Nilai diagnostik pemeriksaan pulasan periodic acid Schiff pada onikomikosis di RSUP Dr.Mohammad Hoesin Palembang (tesis). Palembang: Fakultas kedokteran Universitas Sriwijaya; 2013.

16. Siregar RS, Hartanto $H$, editor (penyunting). Penyakit jamur kulit. Jakarta: EGC; 2005. 